\title{
Caracterização de um Isolado do Pepper mild mottle virus que não Quebra a Resistência do Gene L3 em Capsicum sp.
}

\author{
Marcelo Eiras, Alexandre L. R. Chaves, Silvia R. Moreira, Jansen de Araujo \& Addolorata Colariccio \\ Centro de Pesquisa e Desenvolvimento de Sanidade Vegetal, Instituto Biológico, Av. Conselheiro Rodrigues Alves, 1252, \\ CEP 04014-002, São Paulo, SP, e-mail: eiras@biologico.sp.gov.br
}

(Aceito para publicação em 08/09/2004)

Autor para correspondência: Marcelo Eiras

EIRAS, M., CHAVES, A.L.R., MOREIRA, S.R., ARAUJO, J. \& COLARICCIO, A. Caracterização de um isolado do Pepper mild mottle virus que não quebra a resistência do gene L3 em Capsicum sp. Fitopatologia Brasileira 29:670-675. 2004.

\section{RESUMO}

Sementes de pimenta (Capsicum baccatum) 'Dedo de Moça' destinadas ao plantio comercial e adquiridas no município de São Paulo, SP, analisadas quanto à presença de vírus, por meio de testes biológicos e sorológicos revelaram-se infetadas por uma estirpe do Pepper mild mottle virus (PMMoV). Para confirmar a identidade do isolado, promoveu-se a RT-PCR com oligonucleotídeos que flanqueiam a ORF da capa protéica de espécies do gênero Tobamovirus do subgrupo 1. Os fragmentos de DNA amplificados, quando seqüenciados e comparados com outros isolados de tobamovírus depositados no GenBank, apresentaram valores de identidade de nucleotídeos entre 94 e 100\% com outras seqüências de $\mathrm{PMMoV}$, inferiores a $75 \%$ para as demais espécies de tobamovírus do subgrupo I (Tobacco mosaic virus, Tomato mosaic virus e Odontoglossum ringspot virus) e $65 \%$ para os tobamovírus dos subgrupos II e III. O PMMoV-BR revelou 100\% de identidade com isolados japoneses, sugerindo que este patógeno pode ter sido introduzido daquele país. A seqüência de aminoácidos deduzidos da capa protéica indicou também, que este isolado não é capaz de quebrar a resistência do gene L3 de Capsicum spp. Fato confirmado pelos sintomas causados nas hospedeiras diferenciais de Capsicum spp., verificando-se que este isolado não foi capaz de infetar plantas de C. chinense (L3) e C. chacoense (L4). Estes resultados confirmaram a importância da caracterização dos isolados de tobamovírus, fundamental para adequação de medidas de controle, principalmente, prevenindo a entrada e posterior disseminação do patógeno em novas áreas de cultivo.

Palavras-chave adicionais: Tobamovirus, pimenta, pimentão, seqüenciamento.

\section{ABSTRACT}

Characterization of a non-L3 gene-resistance breaking Pepper mild mottle virus isolate in Capsicum

A strain of Pepper mild mottle virus (PMMoV) was identified by biological and serological analysis of pepper (Capsicum baccatum) 'Dedo de Moça' seeds from São Paulo, SP, Brazil. To confirm these results, RT-PCR was performed with specific primers flanking the coat protein (CP) ORF of tobamoviruses in subgroup 1. The DNA-amplified fragments, when sequenced and compared with other tobamovirus CP sequences stored in the GenBank, showed nucleotide similarity between 94 to $100 \%$ with other PMMoV CP sequences, and below $75 \%$ with the subgroup I tobamovirus species (Tobacco mosaic virus, Tomato mosaic virus and Odontoglossum ringspot virus) and $65 \%$ with species in the subgroups II and III. The Brazilian isolate showed $100 \%$ identity with a Japanese isolate, strongly suggesting that this pathogen could have been introduced from that country. This fact confirms the importance of the isolate's characterization, in order to establish adequate control measures to guarantee healthy seed interchange and to avoid the introduction and spread of tobamoviruses into new growing areas. The deduced $\mathrm{CP}$ aminoacids sequence showed that the PMMoV-BR was not capable to overcome L3 gene resistance. This fact was confirmed by the inoculation and reaction of differential Capsicum species. The Brazilian isolate was not able to infect $C$. chinense (L3) and $C$. chacoense (L4).
Do gênero Tobamovirus fazem parte 17 espécies de vírus distribuídas em três subgrupos, sendo o Pepper mild mottle virus (PMMoV) pertencente ao subgrupo 1, juntamente com o Tobacco mosaic virus (TMV), o Tomato mosaic virus (ToMV), o Tobacco mild green mosaic virus (TMGMV) e o Odontoglossum ringspot virus (ORSV). Esta subdivisão é determinada em função da origem da montagem da partícula, número de nucleotídeos presentes entre duas diferentes ORFs, análise filogenética e hospedeiras, sendo o subgrupo 1 denominado subgrupo das solanáceas, o 2 das crucíferas e o 3 das cucurbitáceas (Lartey et al., 1996).

A maioria das espécies deste gênero apresenta distribuição mundial em regiões de clima temperado e tropical e é transmitida por contato mecânico, decorrente das práticas culturais, permanecendo em resíduos vegetais, no solo ou na água por longos períodos, não havendo, até o momento, vetores biológicos conhecidos. Podem ser disseminados pelas sementes, infestando a superfície do tegumento, mucilagem externa, testa e endosperma, mas não são transmitidos por pólen. No Brasil, há somente relatos da ocorrência de espécies do gênero Tobamovirus pertencentes ao subgrupo 1: o TMV, o ToMV, o ORSV (Alexandre et al., 2000; Moreira et al., 2003), e mais recentemente, o PMMoV em pimenta (Capsicum baccatum L.) e pimentão (Capsicum annuum L.) 
no Estado de São Paulo (Kobori et al., 2001; Cezar et al., 2003; Eiras et al., 2003).

Em função do comportamento frente aos genes de resistência L (L1, L2, L3 e L4), presentes em espécies e cultivares de Capsicum spp., os tobamovírus são classificados em diferentes patótipos (Velasco et al., 2002). O gene L1, presente em pimentão 'Magda' confere resistência ao patótipo 0 (P0), correspondente ao ToMV; o gene L2, presente em pimentão 'Tisana' confere resistência ao patótipo $\mathrm{P} 1$ correspondente ao ToMV e ao Paprika mild mottle virus (PaMMV). As estirpes do PMMoV espanhola (PMMoV-S) (Garcia-Luque et al., 1990) e japonesa (PMMoV-J) (Kirita et al., 1997), denominadas de patótipos $\mathrm{P} 12$ são capazes de infetar cultivares que apresentam os genes L1 e L2 ( $C$. frutescens L.). Já os patótipos P123, correspondentes ao PMMoV-Italian (estirpe italiana) (Garcia-Luque et al., 1993) e PMMoV-Ia (estirpe espanhola) (Velasco et al., 2002), são capazes de infetar cultivares que apresentam os genes L1, L2 e L3 (C. chinense Jac.). As duas últimas estirpes têm sido responsáveis por importantes perdas em cultivos de Capsicum spp. na Europa (Letschert et al., 2002).

Recentemente, Velasco et al. (2002) e Letschert et al. (2002) descreveram métodos rápidos para diferenciar os isolados de tobamovírus capazes ou não de quebrar a resistência do gene L3 por meio de RT-PCR seguida de RFLP. Estas metodologias foram baseadas na seqüência de nucleotídeos da capa protéica, sendo que os isolados que quebram a resistência deste gene (patótipos P123) apresentam um sítio de restrição para a endonuclease EcoRI. Esta pequena diferença no genoma também tem reflexo na proteína, pela troca de metionina (Met) por asparagina (Asn), na posição 139.

Portanto, o presente trabalho teve como finalidade, além de identificar e caracterizar o isolado de tobamovírus (nomeado como PMMoV-BR) presente em sementes de pimenta, por meio de ensaios biológicos aliados a técnicas sorológicas e moleculares para a correta identificação do patógeno, também compará-lo com outros isolados responsáveis por quebra ou não de resistência conferida pelo gene L3 em espécies de Capsicum.

Para tal, sementes comerciais de pimenta 'Dedo de Moça', adquiridas no município de São Paulo (SP), foram semeadas e as plântulas mantidas em condições controladas e analisadas quanto à presença de vírus. Visando à manutenção da fonte de vírus, utilizaram-se como inóculo as plântulas de pimenta com sintomas de mosaico que foram maceradas em solução sulfito de sódio $0,5 \%, \mathrm{pH} 6,0$, na proporção de $1: 5$ (g:ml) com carborundum (400 mesh) como abrasivo e friccionadas nas folhas de plantas indicadoras pertencentes às espécies Nicotiana tabacum L. 'White Burley', pimentão 'Magnata', Chenopodium amaranticolor Coste \& Reyn. e tomateiro (Lycopersicon esculentum Mill.) 'Santa Clara', as quais foram mantidas em casa de vegetação e posteriormente armazenadas sobre cloreto de cálcio a $-20{ }^{\circ} \mathrm{C}$.

Extrato vegetal de folhas sintomáticas de pimentão 'Magnata' experimentalmente infetadas, foi utilizado para inoculação mecânica (conforme descrito acima) das seguintes espécies: pimentão 'Magnata', 'Natalie'; pimenta 'Dedo de Moça'; tomateiro 'Santa Clara' e 'Microtom'; Nicotiana glutinosa L., N. rustica L., N. sylvestris Speg. \& Comes., N. clevelandii Gray, N. tabacum 'White Burley'; Petunia hybrida Vilm.; C. amaranticolor e C. quinoa Willd. Após a inoculação, as plantas foram mantidas em casa de vegetação para a observação dos sintomas. Na ausência de sintomas, foram feitos testes de recuperação do vírus, por meio de inoculação mecânica em plantas de pimentão 'Magnata', a fim de se verificar a ocorrência de latência.

Plantas de Capsicum spp. apresentando reações diferenciais frente aos genes de resistência L (L1, L2, L3 e L4) encontrados em pimentão 'Early California Wonder' $\left(\mathrm{L}^{+} \mathrm{L}^{+}\right)$, pimentão 'Bruinsma Wonder' $\left(\mathrm{L}^{1} \mathrm{~L}^{1}\right)$, C. frutescens 'Tabasco' ( $\left.\mathrm{L}^{2} \mathrm{~L}^{2}\right)$, C. chinense 'PI 159236' $\left(\mathrm{L}^{3} \mathrm{~L}^{3}\right), C$. chacoense Hunz. 'PI 260429' ( $\left.\mathrm{L}^{4} \mathrm{~L}^{4}\right)$ e plantas de N. tabacum 'White Burley' foram mecanicamente inoculadas e mantidas em casa de vegetação para observação dos sintomas. Após a manifestação dos sintomas, as plantas foram submetidas a testes de recuperação biológica e ELISA-PTA com o antisoro contra PMMoV para a confirmação da presença do vírus.

Utilizou-se o ELISA indireto para a identificação do vírus empregando-se anti-soros contra a capa protéica de três espécies do gênero Tobamovirus: ToMV, TMV e o PMMoV. Foram submetidas ao PTA-ELISA amostras de sementes e plântulas provenientes do material original, bem como amostras foliares sintomáticas de pimenta e pimentão, experimentalmente, infetadas e sadias (controle negativo). Todas as amostras foram previamente maceradas em nitrogênio líquido e posteriormente homogeneizadas em tampão de cobertura. Após as reações imuno-enzimáticas, foram realizadas leituras de absorbância $\left(\mathrm{A}_{405 \mathrm{~nm}}\right)$. Consideraram-se positivas as leituras obtidas de material infetado que apresentavam valores três vezes superiores aos controles negativos.

Para a extração de RNAs totais, $1 \mathrm{~g}$ de amostras foliares de pimentão infetado com o isolado PMMoV-BR apresentando mosaico brando e nanismo, foram submetidas ao procedimento descrito por Moreira et al. (2003). Amostras de RNAs totais de folhas de pimentão sadias constituíram o controle negativo.

A RT-PCR foi efetuada partindo-se de $1 \mu \mathrm{g}$ de RNAs totais extraídos e utilizando-se oligonucleotídeos iniciadores (PAS1 - 'antisense'; e PS1 - 'sense') que flanqueiam a ORF da capa protéica $(\mathrm{CP})$, desenhados por meio do alinhamento das seqüências de nucleotídeos de diferentes espécies do gênero Tobamovirus já seqüenciadas (Alexandre et al., 2000). Para a PCR, foram utilizados os reagentes do kit Taq DNA Polymerase recombinant (Gibco BRL), seguindo as recomendações do fabricante. Os fragmentos de DNA amplificados foram visualizados em gel de agarose a 1,0\% $(\mathrm{p} / \mathrm{v})$ corado com brometo de etídeo sob luz ultravioleta. Os produtos amplificados via RT-PCR foram diretamente seqüenciados pela técnica de reação de terminação em cadeia, utilizando-se um Kit comercial de seqüenciamento (Applied Biosystem) seguindo-se as recomendações do fabricante. $\mathrm{O}$ alinhamento das seqüências obtidas nos dois sentidos foi feito 
com o auxílio do programa Sequencer 3.1 (Gene Codes Corporation) e as comparações, com as seqüências existentes no GenBank, foram feitas com o programa BLASTn, disponível no endereço http://www.ncbi.nlm.nih.gov/BLAST.

As seqüências de nucleotídeos e aminoácidos deduzidos foram alinhadas com o programa Clustal X 1.8 com outras seqüências de isolados de PMMoV e ToMV, TMV, ORSV e Cucumber green mottle mosaic virus (CGMMV) depositadas no GenBank, sendo obtido um dendrograma utilizando-se o programa Mega 2.1 das seqüências de nucleotídeos. Utilizou-se também o programa GeneDoc para o cálculo dos valores de identidade das seqüências de nucleotídeos da CP e para a ilustração do alinhamento das seqüências de aminoácidos deduzidos. As seqüências de nucleotídeos e aminoácidos deduzidos do PMMoV-BR, obtidas neste trabalho, foram depositadas no GenBank com o código de acesso AF525080.

Os sintomas observados nas plantas indicadoras foram típicos aos induzidos pelos tobamovírus com pontos cloróticos locais em N. glutinosa, N. rustica, $N$. sylvestris e P. hybrida. Com a exceção da ausência de sintomas sistêmicos em $N$. tabacum 'WB' e imunidade de tomate, características do PMMoV, foi possível concluir que as sementes de pimenta 'Dedo de Moça' estavam contaminadas por uma única espécie de tobamovírus. Além disso, em PTA-ELISA, houve reação positiva somente com o anti-soro contra o PMMoV.

Pelos sintomas induzidos nas diferentes espécies de Capsicum, concluiu-se que o isolado denominado de PMMoVBR pertence ao patótipo P12 em função da ausência de sintomas em C. chinense 'PI 159236' e 'PI 22225' (L $\left.{ }^{3} \mathrm{~L}^{3}\right) \mathrm{e}$ em C. chacoense 'PI 260429' ( $\left.\mathrm{L}^{4} \mathrm{~L}^{4}\right)$. O PMMoV-BR induziu sintomas sistêmicos de mosaico brando em pimentão 'Bruinsma Wonder' $\left(\mathrm{L}^{+} \mathrm{L}^{+}\right)$, 'Early California Wonder' $\left(\mathrm{L}^{1} \mathrm{~L}^{1}\right)$, 'Yolo Wonder' ( $\left.\mathrm{L}^{1} \mathrm{~L}^{1}\right)$, 'Magnata' (Figura 1), 'Magda' $\left(\mathrm{L}^{1} \mathrm{~L}^{1}\right)$, e em $C$. frutescens 'Tabasco' $\left(\mathrm{L}^{2} \mathrm{~L}^{2}\right)$, além de sintomas de mosaico em pimenta 'Dedo de Moça' (Tabela 1).

Fragmentos com $850 \mathrm{pb}$ foram obtidos, via RT-PCR, conforme esperado para espécies de tobamovírus do subgrupo 1. Obtiveram-se valores de identidade de nucleotídeos entre 94 e 100\% com outras seqüências de PMMoV, sendo inferiores a $75 \%$ para as demais espécies de tobamovírus do subgrupo I (TMV, ToMV, TMGMV e ORSV) e $65 \%$ para os tobamovírus dos subgrupos II e III. Ressalta-se que a seqüência da capa protéica do PMMoV-BR revelou 100\% de identidade com o isolado japonês (PMMoV-J) (Kirita et al., 1997), sugerindo que este isolado pode ter sido introduzido daquele país. Este fato confirma a importância da caracterização e comportamento dos isolados de vírus que são transmitidos por sementes, fator fundamental para adequação de medidas de controle, principalmente visando à garantia do intercâmbio de plantas e sementes sadias. Dessa forma, a detecção sorológica (ELISA) deste vírus nas sementes também merece destaque, sendo uma técnica rápida e de baixo custo, podendo prevenir a entrada e posterior disseminação desse patógeno para novas áreas.

Aspectos relacionados à resistência de linhagens avançadas de Capsicum spp. estão sendo investigados. Porém, a seqüência de nucleotídeos da $\mathrm{CP}$ indicou que o PMMoV$\mathrm{BR}$ pertence ao grupo dos vírus que não quebram a resistência do gene L3 ("L3-resistance"). Como pode ser observado (Figura 2) por meio do alinhamento de aminoácidos deduzidos, nota-se que na posição 139 , o isolado brasileiro apresenta uma metionina. A troca de uma metionina (M) por asparagina $(\mathrm{N})$ determina o fenótipo de quebra de resistência do gene L3, representando o aminoácido-chave para tal evento (Velasco et al., 2002). Estes aspectos, relativos à seqüência da CP têm sido, recentemente, investigados por outros autores como diretamente ligados à resistência, sendo a proteína da capa considerada como elicitor de resposta do hospedeiro à infecção (Berzal-Herranz et al., 1995; Tsuda et al., 1998; Hamada et al., 2002).

A análise filogenética das seqüências da $\mathrm{CP}$ de isolados do PMMoV permitiu a sua separação em dois grupos distintos denominados de: grupo "L3-resistance" - patótipos P12, que engloba o isolado brasileiro (PMMoV-BR) e os demais isolados que não são capazes de quebrar a resistência do gene L3; e o grupo "L3 resistance overcoming" - patótipos P123, que engloba o isolado italiano (PMMoV-Italian), espanhol (PMMoV-Ia) e um isolado japonês (PMMoV-Tosa), os quais promovem a quebra da resistência do gene L3 (Figura 3). A quebra de resistência do gene L3 de Capsicum spp. pelos patótipos P123 tem sido objeto de estudo e preocupação porque tem levado a perdas importantes em cultivos de pimenta e pimentão na Europa (Alonso et al., 1991; Letschert et al., 2002; Velasco et al., 2002). Na árvore filogenética nota-se também o isolado PMMoV-Tosa, proveniente do Japão, apresentando $100 \%$ de identidade com o isolado PMMoVItalian, podendo ter sido introduzido da Itália por intercâmbio de material vegetal contaminado (Hamada et al., 2002).

A correta identificação do vírus como pertencente à espécie PMMoV e, por ser este um patótipo que não quebra a resistência do gene L3, fornece subsídios para estratégias de controle e adequação dos programas de melhoramento

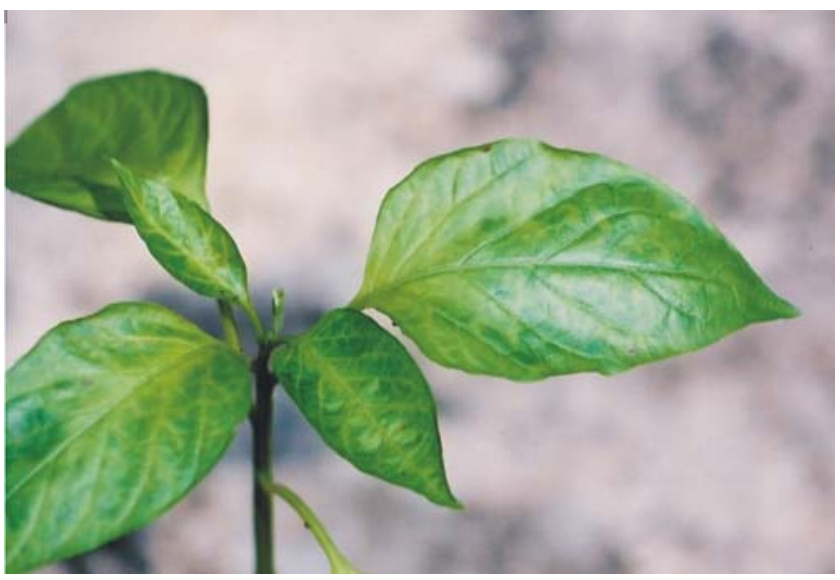

FIG. 1 - Pimentão (Capsicum annuum) 'Magnata' experimentalmente infetado pelo Pepper mild mottle virus (PMMoV-BR) apresentando mosaico brando. 
Caracterização parcial de um isolado do Pepper mild mottle virus

TABELA 1 - Resultado da inoculação com o isolado do Pepper mild mottle virus (PMMoV-BR) em plantas hospedeiras diferenciais e ELISA-PTA

\begin{tabular}{|c|c|c|c|}
\hline Espécie & Sintomas Locais & Sintomas Sistêmicos & ELISA-PTA \\
\hline Nicotiana tabacum White Burley & $\mathrm{LN}$ & $*$ & - \\
\hline N. rustica & $\mathrm{LN}$ & $*$ & - \\
\hline N. sylvestris & $\mathrm{LN}$ & $*$ & - \\
\hline Petunia hybrida & $\mathrm{LN}$ & $*$ & - \\
\hline Lycopersicon esculentum & * & $*$ & - \\
\hline Capsicum annuum BruinsmaWonder $\left(\mathrm{L}^{+} \mathrm{L}^{+}\right)$ & * & $\mathrm{M}, \mathrm{N}$ & + \\
\hline C. annuum East CaliforniaWonder $\left(\mathrm{L}^{1} \mathrm{~L}^{1}\right)$ & * & $\mathrm{M}, \mathrm{N}$ & + \\
\hline C. annuum Yolo Wonder $\left(\mathrm{L}^{1} \mathrm{~L}^{1}\right)$ & * & $\mathrm{M}, \mathrm{N}$ & + \\
\hline C. annuum Magda $\left(\mathrm{L}^{1} \mathrm{~L}^{1}\right)$ & * & $\mathrm{M}, \mathrm{N}$ & + \\
\hline C. annuum Magnata & * & $\mathrm{M}, \mathrm{N}$ & + \\
\hline C. baccatum Dedo de moça & * & Mo, M & + \\
\hline C. frutescens Tabasco $\left(\mathrm{L}^{2} \mathrm{~L}^{2}\right)$ & * & $\mathrm{M}, \mathrm{N}$ & + \\
\hline C. chinense PI $159236\left(\mathrm{~L}^{3} \mathrm{~L}\right)^{3}$ & * & $*$ & - \\
\hline C. chinense PI $22225\left(\mathrm{~L}^{3} \mathrm{~L}^{3}\right)$ & * & * & - \\
\hline C. chacoense PI $260429\left(\mathrm{~L}^{4} \mathrm{~L}^{4}\right)$ & * & $*$ & - \\
\hline
\end{tabular}

Siglas: $\mathrm{LN}=$ lesão necrótica; $\mathrm{M}=$ mosaico; $\mathrm{Mo}=$ mosqueado; $\mathrm{N}=$ nanismo; * = ausência de sintomas; + = positivo; - = negativo

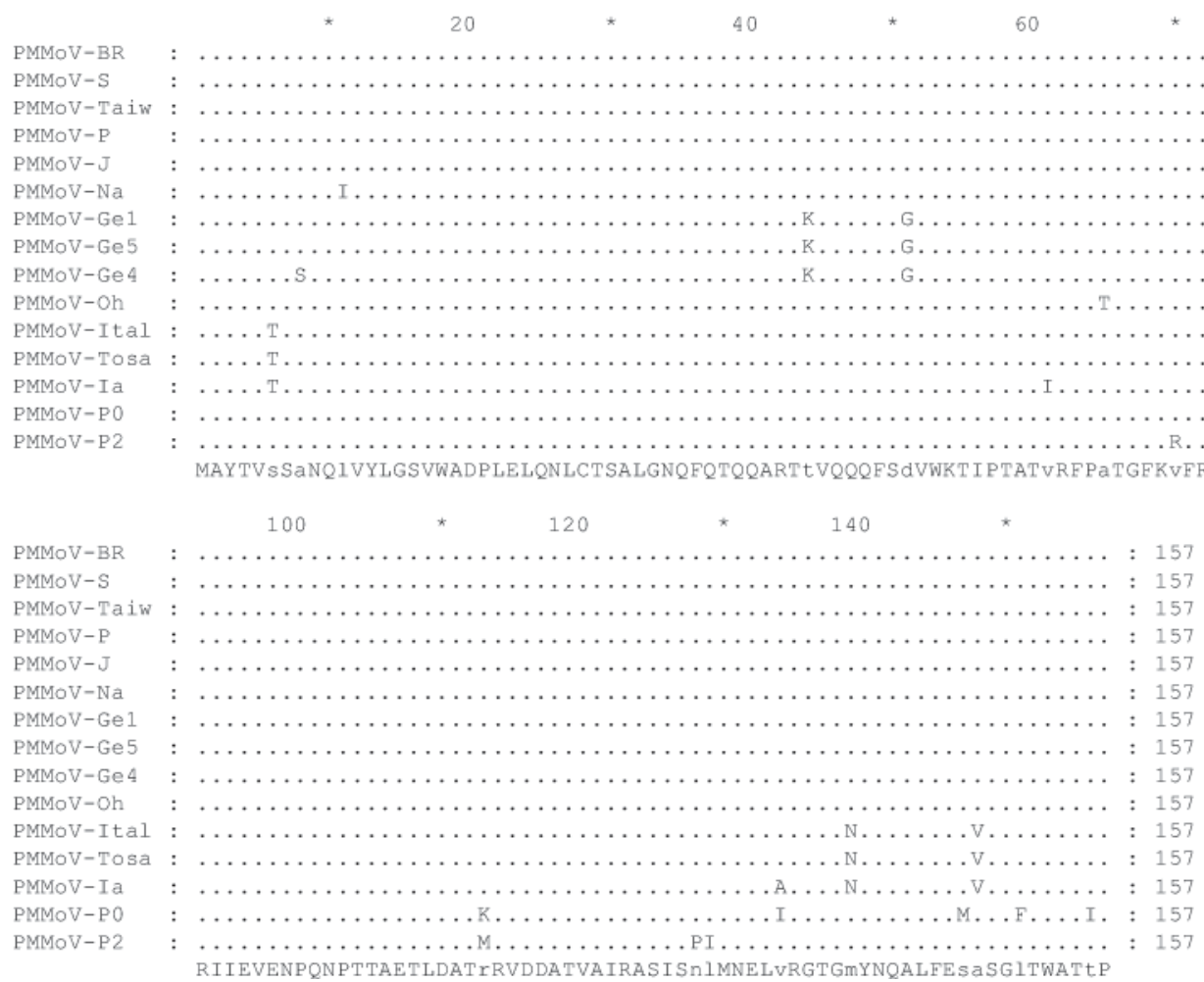

FIG. 2 - Alinhamento múltiplo de aminoácidos deduzidos da capa protéica de isolados de Pepper mild mottle virus (PMMoV), utilizando os programas Clustal X1.8 e GeneDoc. Os códigos de acesso dos isolados estão indicados na Figura 3. Na posição 139 estão os aminoácidoschave que determinam a quebra ( $\mathrm{N}$ - asparagina) ou não ( $\mathrm{M}$ - metionina) da resistência do gene L3. 


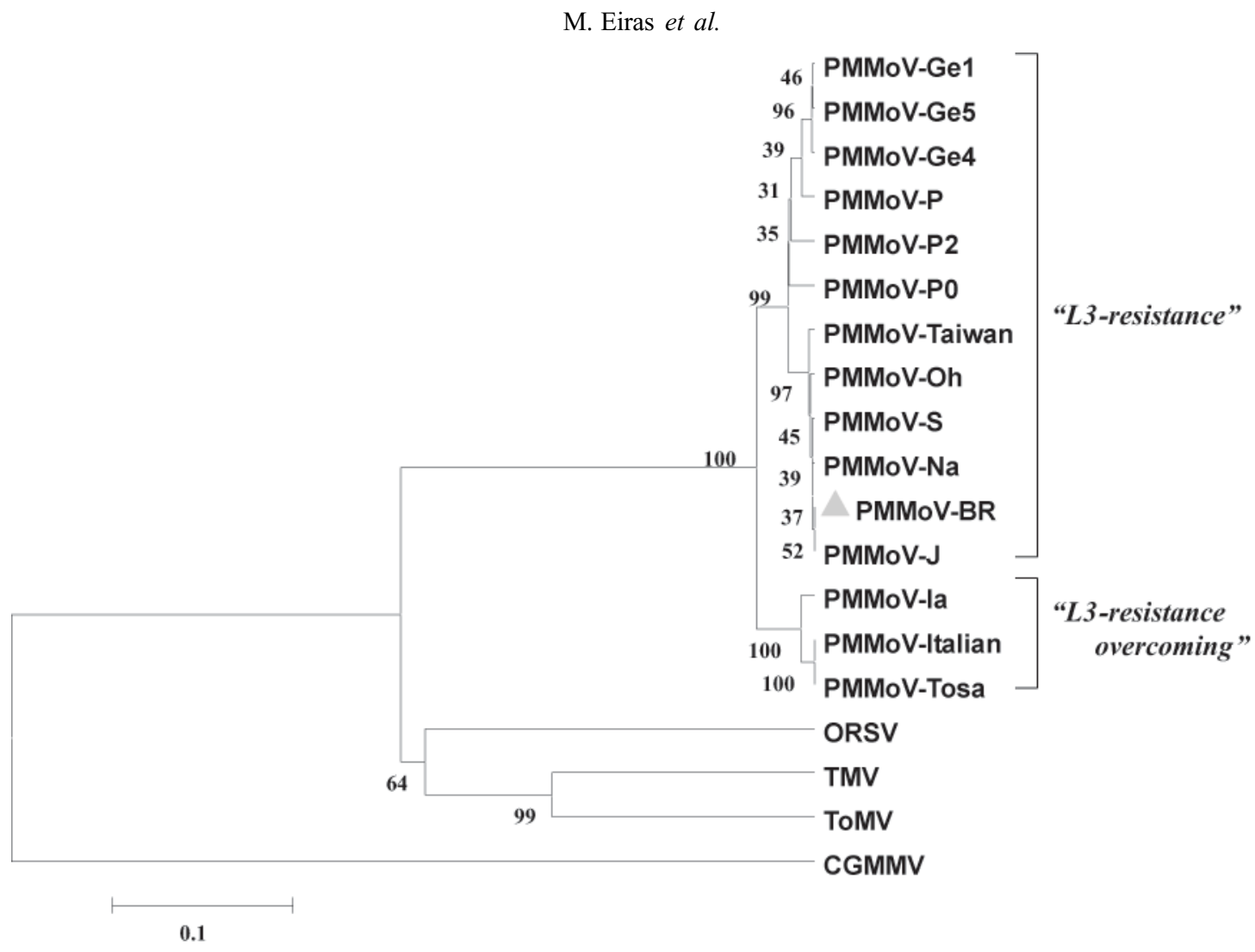

FIG. 3 - Dendrograma obtido com o programa Mega 2.1 (Neighbor-joining) por meio do alinhamento (Clustal X 1.8) das seqüências de nucleotídeos da capa protéica de diferentes isolados do PMMoV e espécies de tobamovírus do subgrupo I. O CGMMV foi utilizado como grupo externo para as análises. Os números indicados nos ramos correspondem aos valores de bootstrap para 1.000 replicações. Os códigos de acesso no GenBank, para cada isolado, estão indicados entre parênteses: PMMoV-BR (AF525080 - isolado caracterizado neste trabalho, evidenciado pelo triângulo cinza); PMMoV-J (AB000709) (Kirita et al., 1997); PMMoV-S (M81413) (Garcia-Luque et al., 1990); PMMoV-Na (AB062054); PMMoV-Taiwan (M87827); PMMoV-Oh (AB062052); PMMoV-P (AB084456); PMMoV-Ge1 (AB062049); PMMoV-Ge5 (AB062051); PMMoV-Ge4 (AB062050); PMMoV-P2 (AF103778); PMMoV-P0 (AF103776); PMMoV-Italian (X72587) (Garcia-Luque et al., 1993); PMMoV-Ia (AJ308228) (Velasco et al., 2002); PMMoV-Tosa (AB062053); ORSV (AF141927); TMV (X70883); ToMV (AF411922); CGMMV (AB015146).

genético. Aparentemente, este vírus não representa um risco potencial para o cultivo de pimenta e pimentão, no Brasil. Porém, medidas importantes devem ser tomadas para evitar a disseminação deste patógeno para novas áreas de cultivo. Além disso, dever-se-á incrementar os cuidados para evitar a entrada do patótipo (P123) do PMMoV que quebra a resistência do gene L3, principalmente evitando a importação de plantas e sementes de Capsicum spp. contaminadas da Espanha, Itália e Japão. Por ser um vírus transmitido por contato mecânico ou sementes contaminadas, o controle baseia-se exclusivamente na utilização de sementes sadias e no manejo adequado da cultura, tanto em campo como em cultivos protegidos.

\section{AGRADECIMENTOS}

Os autores agradecem ao Pesquisador Dr. P. Roggero (Istituto de Virologia Vegetale, Torino, Itália) pelo anti-soro e pelas sementes das hospedeiras diferenciais e à Dra. E.B. Rivas (Instituto Biológico, São Paulo) pelos oligonucleotídeos cedidos.

\section{REFERÊNCIAS BIBLIOGRÁFICAS}

ALEXANDRE, M.A.V., SOARES, R.M., RIVAS, E.B., DUARTE, L.M.L., CHAGAS, C.M., SAUNAL, H., VAN REGENMORTEL, M.H.V. \& RICHTZEHAIN, L.J. Characterization of a strain of Tobacco mosaic virus from Petunia. Journal of Phytopathology 148:601-607. 2000.

ALONSO, E., GARCIA-LUQUE, I., DE LA CRUZ, A., WICKE, B., AVILA-RINCON, M.J., SERRA, M.T., CASTRESANA, C. \& DIAZ-RUIZ, J.R. Nucleotide sequence of the genomic RNA of pepper mild mottle virus, a resistance-breaking tobamovirus in pepper. Journal of General Virology 72:2875-2884. 1991.

BERZAL-HERRANZ, A., DE LA CRUZ, A., TENLLADO, F., DIAZ-RUIZ, J.R., LOPEZ, L., SANZ, A.I., VAQUERO, C., SERRA, M.T. \& GARCIA-LUQUE, I. The Capsicum L3 gene-mediated resistance against the tobamoviruses is elicited by the coat protein. Virology 20:498-505. 1995.

CEZAR, M.A., PAVAN, M.A., KOBORI, R.F. \& KRAUSESAKATE, R. Detecção de tobamovírus em pimentão (Capsicum annuum) por meio de RT-PCR. Summa Phytopathologica 29:59. 2003 (Resumo). 
EIRAS, M., COLARICCIO, A., CHAVES, A.L.R., MOREIRA, S.R. \& ARAUJO, J. Pepper mild mottle Tobamovirus:Caracterização biológica, molecular e identificação sorológica em sementes de pimenta. Summa Phytopathologica 29:60-61. 2003 (Resumo).

GARCIA-LUQUE, I., FERRERO, M.L., RODRIGUEZ, J.M., ALONSO, E., DE LA CRUZ, A., SANZ, A., VAQUERO, C., SERRA, M.T. \& DIAZ-RUIZ, J.R. The nucleotide sequence of the coat protein genes and 3 ' non-coding regions of two resistancebreaking tobamoviruses in pepper shows that they are different viruses. Archives of Virology 131:75-88. 1993.

GARCIA-LUQUE, I., SERRA, M.T., ALONSO, E., WICKE, B., FERRERO, M.L. \& DIAZ-RUIZ, J.R. Characterization of a Spanish strain of pepper mild mottle virus (PMMoV-S) and its relationship to other tobamoviruses. Journal of Phytopathology 129:1-8. 1990.

HAMADA, H., TAKEUCHI, S., KIBA, A., TSUDA, S., HIKICHI, Y. \& OKUNO, T. Amino acid changes in Pepper mild mottle virus coat protein that affect $L^{3}$ gene-mediated resistance in pepper. Journal of General Plant Pathology 68:155-162. 2002.

KiRITA, M., AKUTSU, K., WATANABE, Y. \& TSUDA, S. Nucleotide sequence of the japanese isolate of pepper mild mottle tobamovirus. Annual Phytopathological Society of Japan 63:373376. 1997.

KOBORI, R.F., WIERZBICKI, R., DELLA VECCHIA, P.T., PAVAN, M.A. \& REZENDE, J.A.M. Ocorrência do Pepper mild mottle virus
(PMMoV) em pimentão (Capsicum annuum) cultivado sob estufas no Estado de São Paulo. Fitopatologia Brasileira 26:516. 2001 (Resumo).

LARTEY, R.T., VOSS, T.C. \& MELCHER, U. Tobamovirus evolution: genes overlaps, recombination and taxonomic implications. Molecular Biological Evolution 13:1327-1338. 1996.

LETSCHERT, B., ADAM, G., LESEMANN, D.E., WILLINGMANN, P. \& HEINZE, C. Detection and differentiation of serologically cross-reacting tobamoviruses of the economic importance by RT-PCR and RT-PCR-RFLP. Journal of Virological Methods 106:1-10. 2002.

MOREIRA, S.R., COLARICCIO, A., CHAVES, A.L.R., EIRAS, M. \& GALLETI, S.R. Identificação de uma nova estirpe do vírus do mosaico do tomateiro no Estado de São Paulo. Fitopatologia Brasileira 28:602-607. 2003.

TSUDA, S., KIRITA, M. \& WATANABE, Y. Characterization of a pepper mild mottle tobamovirus strain capable of over-coming the L3 gene-mediated resistance, distinct from the resistance resistancebreaking Italian isolate. Molecular Plant Microbe Interactions 11:327-331. 1998.

VELASCO, L., JANSSEN, D., RUIZ-GARCIA, L., SEGUNDO, E. \& CUADRADO, I.M. The complete nucleotide sequence and development of a differential detection assay for a Pepper mild mottle virus (PMMoV) isolate that overcomes $\mathrm{L} 3$ resitance in pepper. Journal Virological Methods 106:135-140. 2002. 